\title{
Care provider's knowledge, attitude and practices toward chronic kidney disease in Jimma Town: Cross-sectional study
} \author{
4364 \\ Kabaye Kumela Goro \\ Jimma University \\ Fantu kerga Dibaba \\ Jimma University \\ Serkadis Debalke \\ Jimma University \\ Meskerem Seboka \\ Jimma University \\ Birtukan Edilu Tufa \\ Jimma University \\ Fanta Gashe Fufa \\ Jimma University \\ Eshetu Mulisa Bobasa \\ Jimma University
}

Amare Desalegn Wolide ( $\sim$ amaju2002@yahoo.com )

Jimma University College of Public Health and Medical Sciences https://orcid.org/0000-0002-6056-

\section{Research article}

Keywords: Care providers, Chronic Kidney Disease, Kidney Disease

Posted Date: July 24th, 2019

DOI: https://doi.org/10.21203/rs.2.11891/v1

License: (c) (i) This work is licensed under a Creative Commons Attribution 4.0 International License.

Read Full License 


\section{Abstract}

Introduction:Chronic kidney disease (CKD) is a common and growing health problem that requires adequate knowledge by health care providers to reduce the progress of the diseases. Thus, this study is aimed to asses the care provider's knowledge, attitude, and practices toward CKD. Method: Crosssectional study was conducted among 326 care providers at Jimma University Specialized hospital and three medium to higher clinics found in Jimma Town. Collected data entered to Epi-Data version 3.1 and exported to SPSS version 21 for windows for data analysis. Descriptive statistics and generalized linear modal were used to analyze the data. Result:The mean age and service year of the participants were $29.68( \pm 4.877)$ and $4.28( \pm 4.561)$, respectively. The overall weighted knowledge, attitude and practice score of the study participant was $9.0971(8.77,9.42), 2.53(2.4,2.65), 10.14(9.94,10.33)$ respectively. More than half of the respondents 191 (58.6\%) had the knowledge that eGFR (estimated Glomerular Filtration Rate) is a better way to assess kidney function. Many 215(66.0\%) knew the five-stage and the risk factors of CKD. Above 250 study participant knew late detection and referral would increase kidney disease complication. In addition, $275(84.4 \%)$ of them are worried about treatment cost related to CKD. Over half of the care providers, $238(73.0 \%)$ believed that the Ethiopian ministry of health gave less attention to the problem. Furthermore, 234(71.8\%) are interested to study more on CKD management. Majority 256(78.5\%), very likely or likely refer patient to senior physician and Nephrologist. Conclusion: Care provides knowledge was found to be above moderate level and many had the knowledge on the basic function of the kidney, risk factors, treatment, and management of CKD. Many are worried about treatment cost and interested to learn about CKD primary from textbook and internet. The majority had a practice of referring patients to nephrologists or to a senior physician. Many care providers had a frequent discussion on the prevention strategies of CKD.

\section{Introduction}

Chronic kidney disease (CKD) is a worldwide epidemic health problem of increasing prevalence and costing an enormous burden on healthcare systems [1-3]. The worldwide increase of CKD needs a well organized preventive strategy mainly by detecting the risk factors [4-7]. According to the American Heart Association( AHA) statement released in 2013 states that CKD is a major risk factor for coronary disease [8-12]. Earlier-stage CKD can also lead to several complications related to anemia and bone mineral metabolism disorders [13]. Despite these known adverse consequences of CKD, the vast majority of the people remain unaware of the disease [14-16]. Kidney disease (KD) can be diagnosed with simple laboratory procedure. However, peoples practice toward testing (screening) themselves to know the status of CKD is extremely very low. In addition, awareness of CKD remains unacceptably low among care provider's [17-21]. Earlier recognition of CKD by nephrologists can slow the progression of the disease [22-26]. However, late evaluation of CKD patients by nephrologists would increase renal failure [27-30]. Most patients with CKD seeking treatment in the tertiary hospitals are mostly seen by a non-nephrologist. The nephrologist has relatively sufficient awareness related to CKD diagnosis than non-nephrologist [15, 31]. According to the unpublished study renal disease covers $1.2-6 \%$ of adult hospital medical 
admissions in Ethiopia. Chronic glomerulonephritis, diabetes, and hypertension are the leading causes of chronic kidney disease in Ethiopia. In addition, besides the low number of nephrologists in the country, very low level of awareness about kidney diseases, their risk factors, and management of CKD among care providers are believed to be low. Thus, this study proposed to see the level of care providers knowledge, attitude and practices (KAP) toward CKD. Farther more, the investigators believe that the study will bring change in the area by identifying gaps for future direction and better patient approach regarding CKD management.

\section{Methods}

\section{Study Design and Study Setting}

A cross-sectional survey was conducted at Jimma University Specialized Hospital (JUSH) and three main higher private clinics from February 25, 2018, to June 21, 2018. All are located at Jimma town.

\section{Sample Size and Sampling Method}

The sample size was determined based on the single population proportion formula using $Z 2 \times p \times q / d 2$ with the assumption of the prevalence of $50 \%$ for knowledge, attitudes, and practices (KAP) of chronic kidney disease, a $95 \%$ confidence interval and a $5 \%$ margin of error. Finally, adding a $10 \%$ non-response rate; the total sample size was 422 . Sampling was done by the non-probability method. All health care professionals with a bachelor's degree in health sciences, general practitioner, resident doctors, and specialist doctors were eligible for the study.

\section{Method of Data Collection}

We developed a questionnaire on the basis of a literature review to include items assessing KAP on CKD. The content of the questionnaire was assessed by the professionals who are expert in the area. A total of 40 volunteer health care providers were involved in the pre-test. The data collectors and supervisors discussed the questionnaire thoroughly before data collection. The final version administered as part of this study consisted of 25 items divided into three conceptual domains: knowledge, attitudes, and practices. Knowledge domain comprised fourteen items and each was categorized into two point response scale ('Yes' and'No'). Attitude domain contained four questions with two major categorical response scale ("Agree" and "Disagree") to test care providers belief. Lastly, the practice domain consisted of seven items with a four-point Likert-scale ('Very Unlikely', 'Unlikely', 'Likely' and 'Very Likely').

\section{Statistical Analysis}

The International Business Machines Corporation-Statistical Package for Social Sciences program version 23 (IBM-SPSS Statistics 21) was used for data analysis. The data were expressed as means \pm standard deviation (SD) for continuous variables and as frequencies (percentages) for categorical 
variables. Knowledge score and crude associations were assessed using generalized linear model. The possible presence of multicollinearity between independent variables was explored based on the variance inflation factor (VIF). Internal consistency of all CKD Index sub-scales (i.e. knowledge, attitude, practice scales) was assessed using Cronbach's alpha greater than 0.62. All odds ratios were reported with a $95 \%$ confidence interval. All P values were considered significant at $<0.05$.

\section{Result}

\section{Participant characteristics}

A total 326 health care professionals were involved and the majority of the participants were male 227(69.6\%) and general practitioners 96(29.4\%). The mean age and service year of the participants were $29.68( \pm 4.877)$ and $4.28( \pm 4.561)$ respectively. The overall weighted knowledge, attitude and practice score of the study participant was $9.0971(8.77,9.42), 2.53(2.4,2.65), 10.14(9.94,10.33)$ (table 1).

\section{Knowledge}

Male participants had a higher knowledge of $9.54(9.17,9.91)$ than female. Residents $10.1(9.49,10.65)$ had higher knowledge score than other professionals. In addition, Male sex $0.875(0.204,1.547)$ residents $1.84(0.979,2.694)$ and specialist $1.72(0.802,2.646)$ showed significant linear associations with the crude knowledge score of chronic kidney disease (table 1 ).

Majority of the respondents 191 (58.6\%) had knowledge that eGFR (estimated Glomerular Filtration Rate) is a better way to assess the severity of kidney disease. In addition, $180(55.2 \%)$ of the participants also had a knowledge that eGFR helped in referral to a nephrologist (Q2). Regarding the age-related reduction in eGFR without kidney disease, the highest proportion of the participants $202(62.0 \%)$ responded that they don't think it leads to low eGFR with normal serum creatinine and normal urine analysis (Q3). Risk factors and complications of CKD is concerned, 298(91.4\%) of them had knowledge that diabetes and hypertension are possible risk factors of CKD. Farther more, chronic illness, long term alcohol consumption and anemia are also considered as possible risk factors of CKD believed by health care professionals (table 2).

\section{Attitude}

Majority of the study participants $275(84.4 \%)$ agreed that they worry about treatment cost for CKD (Q1). In the same extent, $219(67.2 \%)$ of participants also believed that CKD is a major public health problem in Ethiopia (Q2) and 238(73.0\%) of the participants disagree that ministry of health is working hard in the prevention of the disease (Q3). Furthermore, 234(71.8\%) participants agreed that they need more education on CKD and eGFR (Q4) (table 3).

\section{Practices}


Majority of the participants $256(78.5 \%)$, Very likely or likely refer patient with CKD to senior physician and Nephrologist (Q1). However, 280(85.9\%) and 245(75.2\%) of participants Very Unlikely and Unlikely responded that they refer patients to get care from a traditional healer and treat themselves at home respectively (Q2 and Q3). In addition, many of the participants 260(79.8\%) responded that their health center Very Unlikely or Unlikely prepare a weekly/monthly program focusing on the provision of health information regarding kidney disease (Q7) (Table S1).

\section{Discussion}

Overall, the aims of this study highlight the areas that need to be worked upon in order to improve the quality of care for patients with CKD. Health care providers involved in this study had enough knowledge score about CKD $(9.0971(8.77,9.42))$. Majority of physicians knew eGFR for the diagnosis of CKD and helped them to refer patients to nephrologists. However, many didn't know the standard treatment guidelines and the Modification of Diet in Renal Disease (MDRD) equation used for the calculation of eGFR. This finding has a similarity with the study conducted at a Tertiary Care Hospital in Pakistan [33, 34]. In Ethiopia because of the poor infrastructure, poor laboratory facility and shortage of manpower in the area, physicians frequently use urine and serum creatinine as a means of CKD diagnosis. However, serum creatinine and urine diagnosis may not truly indicate the different stage of CKD, because creatinine level might increases in the blood after high protein ingestions, intense exercise and after taking some drugs such as Cimetidine, Trimethoprim, Pyrimethamine, Salicylates, Phenacemide, Corticosteroids, and Vitamin D derivatives $[35,36]$. Increasing evidence indicates that the CKD burden is increasing in developing countries. The incidence of CKD in Ethiopia is rising because of increased risk factors such as high blood pressure and diabetes mellitus [37-38]. In our study, the majority of the care providers knew the possible risk factors of CKD such as diabetes mellitus, hypertension, cardiovascular disorders, and anemia and long term alcohol consumptions. This finding got a similarity with the study conducted in the USA [40-42]. Pharmacological treatment is one of the ways to treat patients with CKD before the advancement of the disease to the end stage. A variety of drugs such as $\beta$-Blockers, Thiazide Diuretics, and Angiotensin Converting Enzyme (ACE) inhibitors and others are administered by physicians to help patients to stay relatively healthy. Dialysis and kidney transplant are the only options that patients must to take to minimize mortality associated with ESKD. In our study, care providers knew that $\beta$-Blockers, Thiazide Diuretics, and Angiotensin Converting Enzyme (ACE) inhibitors are some of the drugs given to patients with CKD to minimize the effect of the disease before the patient went for dialysis and Kidney translation. The same finding has been reported by Rubeen K.Israni et al 2009 [43-45]. In the current study, care providers showed a strong interest in learning about eGFR and kidney disease. In addition, the majority of the study participants felt kidney problem in Ethiopia is a public health problem that the minister of health gave less attention. As far as practice parameters are concerned, we identified that the majority of the study participants very likely or likely refer patients to Nephrologists. Furthermore, care providers confirm that they had no regular or periodic meeting to discuss kidney disease. However, very likely or likely they had a talk with their patients about the possibility of developing kidney diseases associated with the main disease they bring and also discussed with preventive measures. It is also seen 
that the majority of the participants collect information about CKD from social media or textbooks also they confirm that they did use urine proteins as a major evidence of a diagnosis of CKD.

\section{Conclusion}

The overall weighted knowledge score of the participant on CKD was $9.0971(8.77,9.42)$ which is above a moderate level. Care providers should update themselves on the current advancement of sciences related to CKD treatment and management. Clinical departments should prepare regular meetings to discuss issues related to CKD. Furthermore, patient referral to the appropriate care unite should be encouraged. The ministry of health should give adequate attention to the prevention work as many care providers agreed that CKD is a public health problem in Ethiopia.

\section{Abbreviations}

ACE-Angiotensin Converting Enzyme,

AHA-American Heart Association,

CKD-Chronic Kidney Diseases,

eGFR-estimated Glomerular Filtration Rate,

ESRD-End Stage Renal Disease,

JUSH-Jimma University Specialized Hospital,

KAP-Knowledge, Attitude and Practices,

KD-Kidney Diseases,

MDRD-Modification of Diet in Renal Disease,

SD-Standard Deviation,

SPSS-Statistical Package for Social Sciences,

VIF-Variance Inflation Factor,

\section{Declarations}

\section{Acknowledgements}

The authors would like to kindly acknowledge study participants, data collectors and Jimma University stuffs. 


\section{Funding}

This work was supported by Jimma University, Institute of health sciences research and postgraduate coordinating office. The funders had no role in the design, data collection, or analysis of this study and were not involved in the interpretation of data or in writing the manuscript.

\section{Authors' contributions}

$A D W$ and EMB synthesized the idea and design of the study. ADW, EMB, KK, FK, SD, MS, BE, and FG involved in the data collection. ADW analyze the data and prepared the manuscript. All authors read and approved the final manuscript. All authors read and approved the final manuscript.

\section{Ethics approval and consent to participate}

The Institutional Review Board of Jimma University (IHRPGD/3019/2019.) approved this study. After reviewing a study information sheet, all participants provided written consent to participate in the study.

\section{Consent for publication}

Not applicable.

\section{Competing interests}

The authors declare that they have no competing interests.

\section{Open Access}

This article is distributed under the terms of the Creative Commons Attribution 4.0 International License (http://creativecommons.org/licenses/by/4.0/), which permits unrestricted use, distribution, and reproduction in any medium, provided you give appropriate credit to the original author(s) and the source, provide a link to the Creative Commons license, and indicate if changes were made. The Creative Commons Public Domain Dedication waiver (http://creativecommons.org/publicdomain/zero/1.0/) applies to the data made available in this article, unless otherwise stated.

\section{Publisher's Note}

Springer Nature remains neutral with regard to jurisdictional claims in published maps and institutional affiliations. 


\section{References}

1. McCullough, B., et al. [2010] Sustainable community-based CKD screening methods employed by the National Kidney Foundation's Kidney Early Evaluation Program [KEEP]. American Journal of Kidney Diseases, 57, S4-S8

2. Khalil, A., Frazier, K., Lennie, T. \& Saway, P. [2011]. Depressive symptoms and dietary adherence in patients with end-stage renal disease. Journal of Renal Care, 37, 30-39

3. Lozano R., et al. [2013].Global and regional mortality from 235 causes of death for 20 age groups in 1990 and 2010: a systematic analysis for the Global Burden of Disease Study 2010. Lancet, 380, 2095-2128

4. El Nahas, A. \& MMedSci, A. [2005] Chronic Kidney Disease: the global challenge. Lancet, 365, 331340

5. Khalil \& M. Abdalrahim. Knowledge, attitudes, and practices towards prevention and early detection of chronic kidney disease. International Nursing Review 2014

6. Ibrahim, M. \& Damasceno, A. [2012] Hypertension in developing countries. Lancet, 382, 611-619

7. Wetterhall SF, Olson DR, DeStefano F, et al. Trends in diabetes and diabetic complications, 19801987. Diabetes Care. 1992; 15: 960-7

8. Coresh J, Astor B, Sarnak MJ. Evidence for increased cardiovascular disease risk in patients with chronic kidney disease. Curr Opin Nephrol Hypertens 2004; 13: 73-81.

9. Sarnak MJ, Levey AS, Schoolwerth AC, et al. Kidney disease as a risk factor for development of cardiovascular disease: a statement from the American Heart Association Councils on Kidney in Cardiovascular Disease, High Blood Pressure Research, Clinical Cardiology, and Epidemiology and Prevention. Hypertension 2003; 42: 1050-65.

10. Go AS, Chertow GM, Fan D, McCulloch CE, Hsu CY. Chronic kidney disease and the risks of death, cardiovascular events, and hospitalization. N Engl J Med 2004; 351: 1296-305.

11. Anavekar NS, McMurray JJ, Velazquez EJ, et al. Relation between renal dysfunction and cardiovascular outcomes after myocardial infarction. N Engl J Med 2004; 351: 1285-95.

12. Jafar TH, Levey AS, Jafary FH, White F, Gul A, Rahbar MH, et al. Ethnic subgroup differences in hypertension in Pakistan. J Hypertension 2003; 21:905-12.

13. Shera AS, Rafique G, Khawaja IA, Ara J, Baqai S, King H. Pakistan national diabetes survey: prevalence of glucose intolerance and associated factors in Shikarpur, Sindh Province, Diabetes Med 1995; 12 - 1116-21.

14. Go AS, Chertow GM, Fan D, McCulloch CE, Hsu CY. Chronic kidney disease and the risks of death, cardiovascular events, and hospitalization. N Engl J Med 2004; 351[13]:1296-1305.

15. Snyder S, Pendergraph BE. Detection and evaluation of chronic kidney disease. Am Fam Physician. 2005 Nov 1; 72(9):1723-32.

16. Plantinga LC, Boulware LE, Coresh J, Stevens LA, Miller ER 3rd, Saran R, Messer KL, Levey AS, Powe NR. Patient awareness of chronic kidney disease: trends and predictors. Arch Intern Med 2008; 
168[20]:2268-2275.

17. Nickolas TL, Frisch GD, Opotowsky AR, Arons R, Radhakrishnan J. Awareness of kidney disease in the US population: findings from the National Health and Nutrition Examination Survey [NHANES]1999 to 2000. Am J Kidney Dis 2004; 44[2]:185-197.

18. Coresh J, Byrd-Holt D, Astor BC, Briggs JP, Eggers PW, Lacher DA, Hostetter TH. Chronic kidney disease awareness, prevalence, and trends among U.S. adults, 1999 to 2000. J Am Soc Nephrol 2005; 16[1]:180-188.

19. Paul A. James,;Suzanne Oparil, Barry L. Carter, William C. Cushman, Cheryl Dennison- Himmelfarb, Joel Handler, Daniel T. Lackland, Michael L. LeFevre, Thomas D. MacKenzie, Olugbenga Ogedegbe, Sidney C. Smith Jr, Laura P. Svetkey, Sandra J. Taler, Raymond R. Townsend, Jackson T. Wright Jr, Andrew S. Narva, Eduardo Ortiz. 2014 Evidence-Based Guideline for the Management of High Blood Pressure in Adults Report From the Panel Members Appointed to the Eighth Joint National Committee [JNC 8] . JAMA. 2014; 311[5]:507-520. doi:10.1001/jama.2013.284427.

20. Standards of Medical Care in Diabetes Care. Position Statement of the American Diabetes Association. Diabetes Care, Volume 32, Supplement 1, Jan 2009

21. Levey AS, Atkins R, Coresh J, Cohen EP, Collins AJ, Eckardt KU, Nahas ME, Jaber BL, Jadoul M, Levin A, Powe NR, Rossert J, Wheeler DC, Lameire N, Eknoyan G. Chronic kidney disease as a global public health problem: approaches and initiatives- a position statement from Kidney Disease Improving Global Outcomes. Kidney Int 2007; 72[3]:247-259.

22. Levey AS, Andreoli SP, DuBose T, Provenzano R, Collins AJ. Chronic kidney disease: common, harmful and treatable-World Kidney Day 2007. Am J Nephrol 2007; 27[1]:108-112.

23. Chin HJ, Ahn JM, Na KY, Chae DW, Lee TW, Heo NJ, Kim S. The effect of the World Kidney Day campaign on the awareness of chronic kidney disease and the status of risk factors for cardiovascular disease and renal progression. Nephrol Dial Transplant. 2009 in press. 308371

24. Vassalotti JA, Li S, Chen SC, Collins AJ. Screening populations at increased risk of CKD: The Kidney Early Evaluation Program [KEEP] and the public health problem. Am J Kidney Dis 2009; 53[3 Suppl3]: S107-S114.

25. Lin CL, Chuang FR, Wu CF, Yang CT. Early referral as an independent predictor of clinical outcome in end-stage renal disease on hemodialysis and continuous ambulatory peritoneal dialysis. Renal Failure 2004; 26 [0886-022; 5]:531-537.

26. Kinchen KS, Sadler J, Fink N, Brookmeyer R, Klag MJ, Levey AS, Powe NR. The timing of specialist evaluation in chronic kidney disease and mortality. Ann Intern Med 2002; 137[6]:479-486.

27. Roderick P, Jones C, Drey N, Blakeley S, Webster P, Goddard J, Garland S, Bourton L, Mason J, Tomson C. Late referral for end-stage renal disease: a region-wide survey in the south west of England. Nephrol Dial Transplant 2002; 17[7]:1252-1259.

28. Jungers P, Massy ZA, Nguyen-Khoa T, Choukroun G, Robino C, Fakhouri F, Touam M, Nguyen AT, Grunfeld JP. Longer duration of predialysis nephrological care is associated with improved long-term survival of dialysis patients. Nephrol Dial Transplant 2001; 16[12]:2357-2364. 
29. Tamizuddin S, Ahmed W. Knowledge, attitude and practices regarding chronic kidney disease and estimated GFR in a tertiary care hospital in Pakistan. JPMA May 2010

30. Boulware LE, Troll MU, Jaar BG, Myers DI, Powe NR. Identification and referral of patients with progressive CKD: a national study. Am J Kidney Dis 2006; 48: 192-204

31. Goransson LG, Bergrem H. Consequences of late referral of patients with end-stage renal disease. J Int Med 2001; 250: 154-9

32. https://tenayistilign.com/2013/12/18/the-challenges-of-kidney-disease-in-ethiopia-a-call-fordiaspora-involvement/

33. Chan MR, Dall AT, Fletcher KE, Lu N, Trivedi H. Outcomes in patients with chronic kidney disease referred late to nephrologists: a meta-analysis. Am J Med 2007; 120: 1063-70

34. Sakhuja V, Sud K. End-stage renal disease in India and Pakistan: Burden of disease and management issues. Kidney International Suppl. 2003; 83: S 115-8.

35. Muhammad Anees, Asim Mumtaz, Saleem Uz Zaman Adhmi, Muhammad Ibrahim. Knowledge, attitude and practices (KAP) of chronic kidney disease among medical officers of teaching hospitals of Lahore. Annals Vol 20, Issue 1, Jan -Mar 2014

36. Mahmud M, Hussain N, Kamal A, Samoo ZI, Khan WA. Doctors' Knowledge and Practices Regarding Chronic Kidney Disease at a Tertiary Care Hospital. International Archives of Medicine. 2016 May 30;9.

37. Samra M, Abcar AC. False estimates of elevated creatinine. The Permanente Journal. 2012;16(2):51.

38. Andreev $E$, Koopman M, Arisz L. A rise in plasma creatinine that is not a sign of renal failure: which drugs can be responsible?. Journal of internal medicine. 1999 Sep;246(3):247-52.

39. Abcar AC, Chan L, Yeoh H. What To Do for the Patient with Minimally Elevated Creatinine Level? The Permanente Journal. 2004;8(1):51.

40. Luyckx VA, Tuttle KR, Garcia-Garcia G, Gharbi MB, Heerspink HJ, Johnson DW, Liu ZH, Massy ZA, Moe O, Nelson RG, Sola L. Reducing major risk factors for chronic kidney disease. Kidney International Supplements. 2017 Oct 1;7(2):71-87.

41. Tuso PJ. SERVE Ethiopia. The Permanente Journal. 2009;13(3):51.

42. Moeller S, Gioberge S, Brown G. ESRD patients in 2001: global overview of patients, treatment modalities and development trends. Nephrology Dialysis Transplantation. 2002 Dec 1; 17(12):20716.

43. Agrawal V, Ghosh AK, Barnes MA, McCullough PA. Perception of indications for nephrology referral among internal medicine residents: a national online survey. Clinical Journal of the American Society of Nephrology. 2009 Feb 1;4(2):323-8.

44. Lenz O, Fornoni A. Chronic kidney disease care delivered by US family medicine and internal medicine trainees: results from an online survey. BMC medicine. 2006 Dec; 4(1):30.

45. Plantinga LC, Tuot DS, Powe NR. Awareness of chronic kidney disease among patients and providers. Advances in chronic kidney disease. 2010 May 1; 17(3):225-36. 


\section{Additional Files}

Additional file 1: Table S1. Practice on chronic kidney disease stratified by sex among Health Science Students of Jimma University; N = 395 (2018).

\section{Supplementary Files}

This is a list of supplementary files associated with this preprint. Click to download.

- TablecareprovidersCKD.pdf

- SuppMaterial.pdf 